\title{
BMJ Open Non-medical use of prescription pain relievers among high school students in China: a multilevel analysis
}

\author{
Lan Guo, ${ }^{1}$ Yan Xu, ${ }^{2}$ Jianxiong Deng, ${ }^{2}$ Yuan $\mathrm{He},{ }^{1}$ Xue Gao, ${ }^{2}$ Pengsheng Li, ${ }^{1}$ \\ Hong Wu, ${ }^{1}$ Jinhua Zhou, ${ }^{1}$ Ciyong $\mathrm{Lu}^{1}$
}

To cite: Guo L, Xu Y, Deng J, et al. Non-medical use of prescription pain relievers among high school students in China: a multilevel analysis. BMJ Open 2015;5: e007569. doi:10.1136/ bmjopen-2014-007569

- Prepublication history for this paper is available online. To view these files please visit the journal online (http://dx.doi.org/10.1136/ bmjopen-2014-007569).

LG, YX and JD contributed equally.

Received 4 January 2015 Revised 22 May 2015 Accepted 19 June 2015

\section{CrossMark}

\footnotetext{
${ }^{1}$ Department of Medical Statistics and Epidemiology, School of Public Health, Sun Yat-sen University, Guangzhou, China ${ }^{2}$ Center for ADR Monitoring of Guangdong, Guangzhou, China
}

Correspondence to Dr Ciyong Lu;

luciyong@mail.sysu.edu.cn

\section{ABSTRACT}

Objectives: Given the differences between general high school (GHS) and vocational high school (VHS) students, this study aimed to investigate the lifetime prevalence of non-medical use of prescription pain relievers (NMUPPR) among high school students as well as the associations between NMUPPR and individual-level factors and school category.

Methods: A cross-sectional study was conducted in GHS and VHS students in 2012 in Chongqing, and 11906 students' questionnaires were completed and qualified for the survey. Self-reported NMUPPR and information regarding individual-level determinants and school category were collected. A multilevel multivariate logistic regression model was fitted to explore independent predictors of NMUPPR.

Results: The total lifetime prevalence of NMUPPR was $11.3 \%$, and NMUPPR was more prevalent among VHS students $(15.8 \%)$ compared with GHS students $(9.8 \%)$. Overall, the results indicated that VHS students were more likely to be involved in NMUPPR (adjusted OR $(A O R)=1.64,95 \% \mathrm{Cl} 1.42$ to 1.89 ). Regarding the individual-level predictors of NMUPPR, below-average family economic status was negatively correlated with NMUPPR (AOR=0.77, 95\% Cl 0.60 to 0.98), and students with more pocket money were more likely to be engaged in NMUPPR. Students who had difficult family relationships, had poor relationships with teachers, had parents or friends who engaged in nonmedical prescription drug use, and considered or attempted suicide were more likely to be engaged in NMUPPR.

Conclusions: NMUPPR among high school students is a multidetermined phenomenon. The current findings indicate that VHS students are an important subgroup of adolescents and highlight the need for additional research as well as targeted prevention and intervention programmes for NMUPPR.

\section{INTRODUCTION}

Non-medical use of prescription drugs (including sedatives, tranquillisers, stimulants, and pain relievers) is defined as taking medications without a doctor's prescription, for periods longer than prescribed, or for

\section{Strengths and limitations of this study}

- This rare study has been conducted to describe the prevalence and characteristics of non-medical use of prescription pain relievers (NMUPPR) among general high school and vocational high school students separately.

- Individual-level and school-level factors were involved in a two-level multivariate logistic regression model to select independent predictors of NMUPPR simultaneously.

- Vocational high school students had a higher risk for NMUPPR compared to general high school students.

- The study demonstrated that a student's family-related, school-related and psychosocialrelated factors also influence NMUPPR.

- Although the results cannot be generalised to all adolescents, there are sufficient and representative samples in this study.

reasons other than the medication's intended purpose (eg, 'to experiment' or 'to get high'). ${ }^{1}{ }^{2}$ During the past two decades, the increase in non-medical use of prescription drugs has been a topic of great concern. ${ }^{3}$ Prescription drugs were the second most popular drug among adolescents in the USA according to the 2013 National Survey on Drug Use and Health (NSDUH) ${ }^{4}$ and pain relievers are currently the most abused types of prescription drugs among teens, followed by stimulants, tranquillisers and sedatives. ${ }^{5}$ Notably, according to the report of Monitoring the Future (MTF), $14 \%$ of non-medical prescription pain reliever users are dependent. ${ }^{6}$ High school students, often described as individuals between 10 and 24 years of age, which is roughly the period of adolescence for much of the world, engage in priority health-risk behaviours, including substance use. $^{7}$ Previous studies have reported that high school students have the highest risk of non-medical prescription drug use relative to 
other age groups, ${ }^{48}$ and this finding may reflect youth's perception that prescription drugs are safer, easier to access, and less stigmatising than illicit drugs. ${ }^{9}$ However, it is clear that non-medical prescription drug use among juveniles is a large public health problem with negative consequences, such as depressive disorder, bipolar disorders and anxiety disorder. ${ }^{10}$ Non-medical use of prescription pain relievers (NMUPPR) among adolescents in the USA represents a growing public health problem, ${ }^{11}$ and very few studies have described the characteristics associated with NMUPPR among US high school students. ${ }^{12}$ To the best of our knowledge, no study has described NMUPPR among Chinese high school students, and the recent increased interest in exploring the predictors associated with NMUPPR in Chinese adolescents is warranted.

Prior studies have illustrated many individual-level factors that are associated with NMUPPR among high school students. McCabe's study in the USA suggested that male students were more likely to report NMUPPR than female students in their lifetime $(17.4 \%$ vs $15.7 \%){ }^{1}$ while Boyd's study in a Detroit-area public school district revealed that girls had a higher prevalence of NMUPPR than boys (22\% vs $10 \%)$, and students at higher grade levels were more likely to report NMUPPR.$^{13}$ A study in six European countries indicated that students whose parents and peers engaged in substance use were at a higher risk of NMOPPR, ${ }^{14}$ and a study among Mississippi youth suggested that suicidal behaviours were significantly associated with NMUPPR. ${ }^{15}$

High school is generally categorised into general high school (GHS) and vocational high school (VHS), and VHS students are typically characterised into heterogeneous educational levels, including a significant proportion with little or no educational attainment. ${ }^{16}{ }^{17}$ In the highly academically stratified society, students who graduate from VHS experience discrimination, including fewer employment opportunities or significantly lower salaries compared to those who graduate from GHS. ${ }^{18}$ Prior studies in South Korea and the USA have found that students in VHS have a greater risk for smoking or drinking behaviour than those in GHS, even after controlling for individual-level factors. ${ }^{19} 20$ However, this rare study has been conducted to describe the prevalence and characteristics of NMUPPR among GHS and VHS students separately or to examine the influence of individual-level factors and high school category on NMUPPR simultaneously. Therefore, we conducted a cross-sectional study within a large sample of randomly selected GHS and VHS students in southwest China to assess the lifetime prevalence and characteristics of NMUPPR and to explore the independent predictors of NMUPPR in terms of individual-level factors and school category.

The following three hypotheses were formulated. First, consistent with the results of previous studies, ${ }^{21}{ }^{22}$ we hypothesised that NMUPPR is a major international public health problem among adolescents, and Chinese high school students are no exception. Second, we expected that differences in the demographics and prevalence of NMUPPR between GHS and VHS students are significant and the current status of NMUPPR in VHS students is more serious than that in GHS students. Third, in line with previous findings, ${ }^{21} 2324$ we hypothesised that most family-related, school-related and psychosocial-related factors are related to NMUPPR.

\section{METHODS}

\section{Study design and participants}

A cross-sectional study among GHS and VHS students was conducted in 2012 in Chongqing, located in southwest China. The sample size was calculated for a prevalence of non-medical prescription drug use among Chinese adolescents of $6 \%,{ }^{21}$ an $\alpha$ of 0.05 , a sampling error of 0.005 , an estimate of 3.8114 million high school students in Chongqing. We used a multistage stratified cluster sampling procedure to obtain a representative sample. With adjustment for the clustering design effect and the non-response rate, the resulting calculated sample size was 9014 . In stage 1 , based on the surveillance data on the population of 'non-medical prescription drug users of cough syrup with codeine' during 2010-2011 from the Center for ADR Monitoring of Chongqing, we divided the districts in Chongqing into three categories: (1) high (districts accounting for more than $5 \%$ of this population); (2) middle (districts accounting for $1-5 \%$ of this population) and (3) low (districts accounting for less than $1 \%$ of this population). Then we selected two representative districts (or primary sampling units) from each category by simple randomisation using SAS software. In stage 2, high schools (or secondary sampling units) in each selected district were divided into three categories based on teaching quality: key high school, regular high school and VHS. All high schools in the selected districts were surveyed (including four key high schools, five regular high schools, and four VHS in each of the high and low districts as well as five key high schools, six regular high schools, and three VHS in the middle districts). In total, 29 GHS and 11 VHS within these primary units were selected. In stage 3, two classes (or minimum sampling units) were randomly selected from each grade within the selected schools (figure 1). All available students in the selected classes were invited to participate in our study. Of the 12406 high school students who were invited to participate, 11906 students' questionnaires were completed and qualified for the survey, resulting in a response rate of $96.0 \%$.

\section{Data collection}

To protect the privacy of the students, a rigorously anonymous method for collection of the self-report questionnaires was guaranteed, and the questionnaires were administered by research assistants in the classrooms without the presence of the teachers (to avoid 
Figure 1 Flow chart of the sampling procedure (GHS, general high school; VHS, vocational high school).

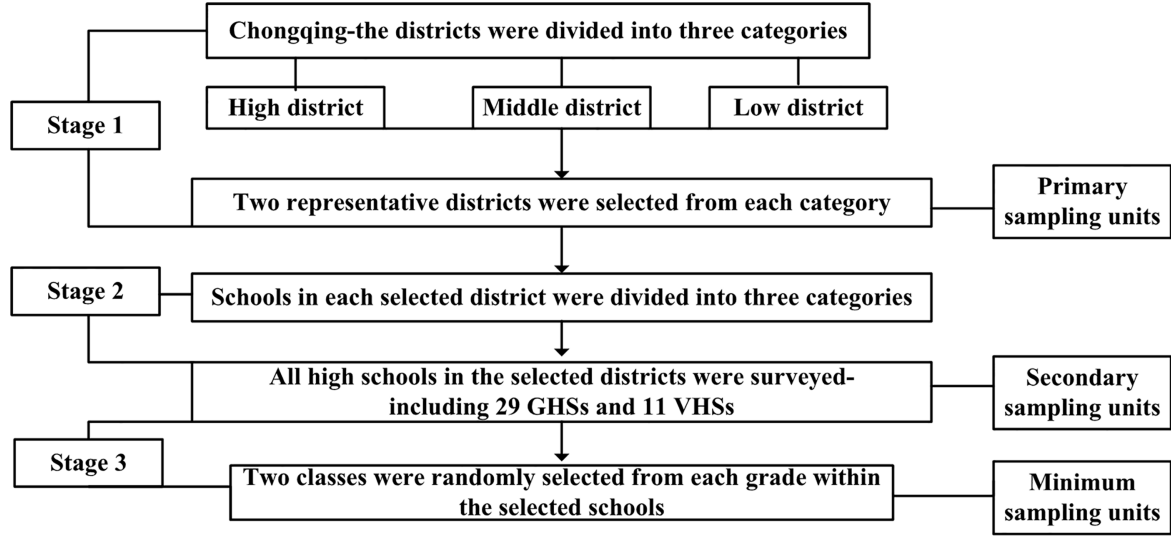

any potential information bias) during $30 \mathrm{~min}$ of the students' regular class time.

\section{Ethics statement}

All the participants were fully informed of the purpose of the survey and were invited to participate voluntarily. Written consent letters were obtained from each participating student who was at least 18 years of age. If the student was under 18 years of age, a written consent letter was obtained from one of the student's parents.

\section{Measures}

Dependent variable

The dependent variable was the lifetime NMUPPR, which was assessed by the following question: 'Have you ever, even once, used the following medications when you were not sick or just for the intended purpose to experiment or to get high without a doctor's prescription?' The question was followed by a list of the following prescription pain relievers. The response categories were 'yes' and 'no'. In this study, we only included four pain relievers: cough syrup with codeine, Percocet, tramadol, and scattered analgesics (commonly used traditional Chinese medicine, such as Ephedra Herb and Aconitum carmichaeli Debx, not only having the function of relieving pain, but also having complex compositions which can make people addicted when reaching a high dose). ${ }^{25}$ The list of medications was developed based on medicines reported to be widely used by adolescent drug abusers in rehabilitation centres and a list provided by the Center for ADR Monitoring of Chongqing.

\section{Independent variables}

The individual-level independent variables included the students' sociodemographic characteristics, familyrelated and school-related factors, alcohol and cigarette use, and psychosocial-related factors. The sociodemographic variables were age, gender, grade and pocket money (the students were asked how much pocket money, on average, they received per month from their parents. The responses were coded as 'less than 100 RMB', '100-299 RMB' or 'more than 300 RMB'). Each student's living arrangement was assessed by asking who lived in the student's primary home. Family economic status was measured by asking about the student's perception of his or her family's current economic status. Family relationships were assessed by asking the students how they judged the relationships between their family members. Academic stress was captured by a single item that asked for a personal appraisal of the student's academic stress relative to that of his/her classmates (responses were coded as 'below average', 'average' or 'above average'). Relationships with classmates or teachers were also assessed based on the students' selfratings (responses were coded as 'poor', 'average' or 'good'). Whether the students' parents or friends engaged in non-medical prescription drug use was assessed by asking the participants the following question: 'Have your parents or friends used prescription drugs when they were not sick without a doctor's prescription during their lifetime?' Alcohol drinking was measured by a single item ('Have you used at least one drink previously and one or more drinks within the past 30 days?'). Cigarette smoking was assessed by asking the respondents the following question: 'Have you smoked at least one cigarette previously and used between 1 and 29 cigarettes within the past 30 days?' Psychosocialrelated factors were assessed by two variables, feeling lonely and suicidal behaviour. Feeling lonely was assessed by asking the students the following question: 'During the past 12 months, how often did you feel lonely each week?' The response options for this question ranged from 1 -never to 4 -over 4 days. Suicidal behaviour was assessed by asking the students the following question: 'During the past 12 months, did you ever seriously consider attempting suicide?' The response options for this question were 1 -never, 2-considered or 3-attempted. In regard to the school-level independent variable, the high school was categorised as a GHS or VHS according to official data that were provided by the city board of education.

\section{Sources of prescription pain relievers}

The sources of obtaining prescription pain relievers for non-medical use were assessed by asking students the 
following multiple-choice question: 'Where did you get prescription pain relievers for non-medical use?' The response options for this question were 1 -from peers, 2 -from family members or 3-from others.

\section{Motivations for NMUPPR}

The motivations for NMUPPR were assessed by asking students the following multiple-choice question: 'Why did you non-medically use prescription pain relievers?' The response options for this question were 1 - to experiment, 2-to get high, 3-to relax or relieve tension, or 4 -other.

\section{Statistical analysis}

Two investigators independently entered all of the data using EpiData software (V.3.1), and all statistical analyses were conducted using SAS (V.9.2). Descriptive analyses were conducted separately in GHS and VHS students to describe the different relationships among the demographic characteristics and the lifetime prevalence of NMUPPR. Subsequently, a two-level multivariate logistic regression model (individuals at level 1 nested within 29 GHS and 11 VHS at level 2) was fitted to estimate variables that were independently predictive of NMUPPR according to the adjusted ORs (AORs) and 95\% CIs. We entered all individual-level and school-level variables as covariates into this regression model (the generalised linear mixed effects model adopting the GLMMIX procedure in SAS) to select the complete and independent predictors of NMUPPR. Statistical significance was evaluated at the $<0.05$ level using two-sided tests. The questionnaires were reasonably complete. The percentage of missing data was less than $2 \%$ for all relevant variables, and missing data were eliminated in the $\chi^{2}$ tests, $\mathrm{t}$ test and two-level multivariate logistic regression analysis.

\section{RESULTS}

Demographic characteristics of GHS and VHS students

The demographic information distributions are illustrated in table 1. The final sample consisted of 11906 high school students, including 8095 (74.7\%) GHS and $3001(25.3 \%)$ VHS students. The students ranged in age from 11 to 23 years, and the mean age was $16.7( \pm 1.2)$ years. The proportion of males was $45.9 \%$. Regarding the individual-level factors, $37.8 \%$ of students considered their family economic status to be below average. A total of $2.9 \%$ of the students reported poor classmate relationships, and $6.2 \%$ had poor relationships with teachers. A total of $13.8 \%$ of the students reported smoking, $71.2 \%$ of the students reported drinking during the past 30 days, and $1.2 \%$ of the students attempted suicide.

\section{Prevalence and characteristics of NMUPPR among GHS and VHS students}

As shown in table 2, we estimated the total prevalence and characteristics of NMUPPR and the subgroup prevalence rates of NMUPPR among GHS and VHS students.
The total lifetime prevalence of NMUPPR was $11.3 \%$, and VHS students had higher rates of lifetime exposure to NMUPPR than GHS students $(15.8 \%$ in VHS students and $9.8 \%$ in GHS students). The prevalence of NMUPPR was $12.2 \%$ among male students and $10.5 \%$ among female students, and male students had a higher prevalence of NMUPPR than female students in GHS and VHS. NMUPPR was more prevalent among those who lived with others, reported above average family economic status, had difficult family relationships, had poor classmate relationships, and had poor relationships with teachers. Additionally, students who had parents or friends who engaged in non-medical prescription drug use had a higher prevalence of NMUPPR. Students who attempted suicide had a much higher prevalence of NMUPPR than those who did not.

\section{Classes, sources and motivations for NMUPPR among GHS and VHS students}

Table 3 shows that the most common non-medically used prescription pain reliever among high school students was scattered analgesics, at approximately 5.8\%, followed by cough syrup with codeine, Percocet and tramadol. In this study, we also found that prescription pain relievers for non-medical use among high school students were most commonly obtained from peers, followed by others and family members. In addition, the most prevalent motivation for NMUPPR among high school students was 'to relax or relieve tension', followed by 'to experiment' and 'to get high'.

\section{Predictors of NMUPPR based on a two-level multivariate logistic regression model}

A two-level multivariate logistic regression model was used to initially examine the individual-level and schoollevel independent predictors of NMUPPR among high school students (table 4). Compared with GHS students, VHS students were more likely to be users of nonmedical prescription pain relievers $(\mathrm{AOR}=1.64,95 \% \mathrm{CI}$ 1.42 to 1.89 ) after controlling for individual-level variables. Regarding the individual-level predictors of NMUPPR, below-average family economic status was negatively correlated with NMUPPR $(\mathrm{AOR}=0.77,95 \%$ CI 0.60 to 0.98 ), and students with more pocket money were more likely to be engaged in NMUPPR. Students who had difficult family relationships (AOR=1.26, 95\% CI 1.02 to 1.54), average relationships with teachers (AOR $=1.50,95 \%$ CI 1.20 to 1.89 ) and poor relationships with teachers (AOR=1.57, 95\% CI 1.23 to 2.01 ) were at a higher risk for NMUPPR compared to the corresponding reference group. Additionally, students having parents who engaged in non-medical prescription drug use $(\mathrm{AOR}=2.31,95 \%$ CI 1.79 to 2.98$)$ or having friends who engaged in non-medical prescription drug use ( $\mathrm{AOR}=1.75,95 \%$ CI 1.38 to 2.22 ) were more likely to be involved in NMUPPR. Additionally, cigarette smoking (AOR=1.53, 95\% CI 1.29 to 1.82), considering suicide (AOR=3.47, 95\% CI 2.34 to 5.15$)$ and attempting suicide 
Table 1 Demographic characteristics of GHS and VHS students

\begin{tabular}{|c|c|c|c|c|}
\hline Variables & Total, n (\%) & GHS, n (\%) & VHS, n (\%) & p Value* \\
\hline Total & $11906(100)$ & 8905 (100) & $3001(100)$ & - \\
\hline \multicolumn{5}{|l|}{ Gender } \\
\hline Male & 5465 (45.9) & $4070(45.7)$ & 1395 (46.5) & \multirow[t]{2}{*}{0.458} \\
\hline Female & $6441(54.1)$ & 4835 (54.3) & $1606(53.5)$ & \\
\hline Age (years)† & $16.7(1.2)$ & $16.8(1.1)$ & $16.5(1.3)$ & $<0.001$ \\
\hline \multicolumn{5}{|l|}{ Grade } \\
\hline 10 & 3942 (33.1) & 2912 (32.7) & 1030 (34.3) & \multirow[t]{3}{*}{0.064} \\
\hline 11 & 3948 (33.2) & 2934 (32.9) & 1014 (33.8) & \\
\hline 12 & $4016(33.7)$ & 2895 (32.5) & 1121 (37.3) & \\
\hline \multicolumn{5}{|l|}{ Living arrangement } \\
\hline With both parents & $6451(54.4)$ & 4994 (56.3) & 1457 (48.9) & \multirow[t]{4}{*}{$<0.001$} \\
\hline With only father or mother & $1899(16.0)$ & $1387(15.6)$ & 512 (17.2) & \\
\hline With others & $3501(29.5)$ & $2492(28.1)$ & 1009 (33.9) & \\
\hline Missing data & $55(0.5)$ & - & - & \\
\hline \multicolumn{5}{|l|}{ Pocket money (RMB) } \\
\hline$<100$ & $5439(45.7)$ & $1361(45.8)$ & $4078(46.1)$ & \multirow[t]{4}{*}{0.491} \\
\hline 100-299 & $4388(36.9)$ & $1090(36.7)$ & 3298 (37.3) & \\
\hline$>300$ & $1985(16.7)$ & $520(17.5)$ & 1465 (16.6) & \\
\hline Missing data & $94(0.8)$ & - & - & \\
\hline \multicolumn{5}{|l|}{ Family economic status } \\
\hline Above average & $851(7.2)$ & $664(7.5)$ & $187(6.3)$ & \multirow[t]{4}{*}{$<0.001$} \\
\hline Average & $6524(55.1)$ & 4987 (56.2) & $1537(51.6)$ & \\
\hline Below average & 4473 (37.8) & 3218 (36.3) & $1255(42.1)$ & \\
\hline Missing data & $58(0.5)$ & - & - & \\
\hline \multicolumn{5}{|l|}{ Family relationships } \\
\hline Good & $8686(73.1)$ & $6589(74.1)$ & 2097 (70.1) & \multirow[t]{4}{*}{$<0.001$} \\
\hline Normal & 2205 (18.6) & $1576(17.7)$ & $629(21.0)$ & \\
\hline Difficult & $991(8.3)$ & 725 (8.2) & $266(8.9)$ & \\
\hline Missing data & $24(0.2)$ & & & \\
\hline \multicolumn{5}{|l|}{ Academic stress } \\
\hline Above average & 1546 (13.0) & $900(10.1)$ & $646(21.6)$ & \multirow[t]{4}{*}{$<0.001$} \\
\hline Average & 4979 (41.9) & 3395 (38.2) & 1584 (52.9) & \\
\hline Below average & $5355(45.1)$ & $4592(51.7)$ & 763 (25.5) & \\
\hline Missing data & $26(0.2)$ & - & - & \\
\hline \multicolumn{5}{|l|}{ Classmate relationships } \\
\hline Good & $6759(56.9)$ & $5201(58.5)$ & $1558(52.1)$ & \multirow[t]{4}{*}{$<0.001$} \\
\hline Average & 4771 (40.2) & 3434 (38.6) & 1337 (44.7) & \\
\hline Poor & $344(2.9)$ & $250(2.8)$ & $94(3.1)$ & \\
\hline Missing data & $32(0.3)$ & & & \\
\hline \multicolumn{5}{|l|}{ Relationships with teachers } \\
\hline Good & $4608(38.8)$ & 3401 (38.3) & 1207 (40.3) & 0.076 \\
\hline Average & $6528(55.0)$ & $4913(55.3)$ & $1615(54.0)$ & \\
\hline Poor & $741(6.2)$ & $571(6.4)$ & $170(5.7)$ & \\
\hline Missing data & $29(0.2)$ & & & \\
\hline Parents engaged in NMUPD & & & & \\
\hline No & $11501(96.6)$ & 8607 (96.7) & 2894 (96.4) & 0.567 \\
\hline Yes & $405(3.4)$ & $298(3.3)$ & $107(3.6)$ & \\
\hline Friends engaged in NMUPD & & & & \\
\hline No & $11363(95.4)$ & 8507 (95.5) & 2856 (95.2) & 0.411 \\
\hline Yes & $543(4.6)$ & $398(4.5)$ & $145(4.8)$ & \\
\hline Cigarette smoking & & & & \\
\hline No & 10297 (86.5) & 7902 (88.7) & 2395 (79.8) & $<0.001$ \\
\hline Yes & 1609 (13.8) & $1003(11.5)$ & $606(20.8)$ & \\
\hline Alcohol drinking & & & & \\
\hline No & $3430(28.8)$ & $2494(28.0)$ & $936(31.2)$ & 0.001 \\
\hline Yes & 8476 (71.2) & $6411(72.0)$ & 2065 (68.8) & \\
\hline Feel lonely & & & & \\
\hline$<1$ day/week & $5807(49.5)$ & $4376(49.8)$ & $1431(48.6)$ & 0.473 \\
\hline & & & & $\overline{\text { Continued }}$ \\
\hline
\end{tabular}


Table 1 Continued

\begin{tabular}{|c|c|c|c|c|}
\hline Variables & Total, n (\%) & GHS, n (\%) & VHS, n (\%) & p Value* \\
\hline 1-4 days/week & 4495 (38.3) & 3340 (38.0) & 1155 (39.2) & \\
\hline > 4 days/week & $1422(12.1)$ & 1064 (12.1) & 358 (12.2) & \\
\hline Missing data & $182(1.5)$ & - & - & \\
\hline \multicolumn{5}{|l|}{ Suicide behaviour } \\
\hline Never & 11276 (94.7) & 8465 (96.2) & $2811(95.0)$ & 0.008 \\
\hline Considered & $344(2.9)$ & $233(2.6)$ & $111(3.8)$ & \\
\hline Attempted & $142(1.2)$ & $104(1.2)$ & 38 (1.3) & \\
\hline Missing data & $144(1.2)$ & - & - & \\
\hline
\end{tabular}

$(\mathrm{AOR}=2.08,95 \%$ CI 1.29 to 3.35$)$ were independent risk predictors of NMUPPR.

\section{DISCUSSION}

To the best of our knowledge, this is the first study to describe NMUPPR among Chinese high school students and to explore potential predictors of NMUPPR in China. The present study significantly contributes to the understanding of NMUPPR among various high school students. The current results provide evidence of significant demographic differences between GHS and VHS students, and these findings led us to conduct a stratification analysis of the prevalence and characteristics of NMUPPR across school type. We found that approximately $11.3 \%$ of the students reported NMUPPR in their lifetime. The total prevalence rate of NMUPPR was higher than that described in a previous report from the 2013 National Survey on Drug Use and Health (NSDUH) in the USA which showed that 4.5 million $(1.7 \%)$ respondents aged 12 or older were non-medical users of prescription pain relievers, ${ }^{4}$ and lower than that described in a study of a Detroit-area public school district, suggesting that approximately $16 \%$ of students had engaged in NMUPPR during their lifetime. ${ }^{13}$ A possible explanation for the variance in the prevalence could be differences in the nature of the samples or the classes of pain relievers. In our research, according to a list provided by the Center for ADR Monitoring of Chongqing suggesting that pain relievers are widely used by adolescent drug abusers in rehabilitation centres, we only included four specific classes of pain relievers. Our results suggested that the most common NMUPPR among total high school students was scattered analgesics, at approximately $5.8 \%$, followed by cough syrup with codeine $(5.5 \%)$. These results are consistent with the study of Wang $e t a l^{21}$ in Guangdong.

Furthermore, consistent with our expectations, the current results demonstrated that VHS students $(15.8 \%)$ had a much higher prevalence of NMUPPR than GHS students $(9.8 \%)$, and that VHS students consistently had a higher prevalence of NMUPPR compared to GHS students regardless of their demographic characteristics. Additionally, the final logistic regression model revealed that students who attended the VHS had a higher risk of NMUPPR compared to those who attended the GHS (AOR $=1.64,95 \%$ CI 1.42 to 1.89 ). This result is consistent with previous findings in China and the USA showing that students who are unable to perform academically on the high school admittance test or are enduring household economic challenges typically enrol in the VHS and that these students are more likely to be involved in substance use. ${ }^{26}$ This study was the first to examine the influence of different high school categories (GHS or VHS) on NMUPPR, although Franke reported that German pupils from vocational schools were at a higher prevalence of non-medical use of prescription stimulants. ${ }^{27}$ According to these findings, preventive and intervention programmes should consider the school category, when developing measures to control the problem of NMUPPR in schools, especially in VHS. A prior study in four German federal states demonstrated that school-based prevention programmes are considered to be one of the most appropriate and suitable strategies for preventing adolescent substance use. $^{28}$

Regarding the individual-level factors, our study first showed that male students had a higher prevalence of NMUPPR than female students $(12.2 \%$ vs $10.5 \%)$; however, after adjusting for other variables, there was no significant association between gender and NMUPPR. The findings on gender and NMUPPR have not been consistent in the previous literature, with some studies showing an association between NMUPPR and female gender, ${ }^{24} 29$ others showing an association between NMUPPR and male gender, ${ }^{30}$ and yet others showing no significant association between gender and NMUPPR. ${ }^{31}$ Additionally, consistent with a prior study in Sweden, ${ }^{24}$ we did not find any association between NMUPPR and age. Prior studies in the USA have shown that there is a significant association between grade and NMUPPR, ${ }^{32} 33$ while the results of our study showed no significant associations between school grade and NMUPPR. It is possible that this result might be related to the fact that the 
Table 2 Prevalence and characteristics of NMUPPR among GHS and VHS students

\begin{tabular}{|c|c|c|c|}
\hline Variables & $\begin{array}{l}\text { Total } \\
\text { NMUPPR, n (\%) }\end{array}$ & $\begin{array}{l}\text { GHS } \\
\text { NMUPPR, n (\%) }\end{array}$ & $\begin{array}{l}\text { VHS } \\
\text { NMUPPR, n (\%) }\end{array}$ \\
\hline NMUPPR & $1342(11.3)$ & $869(9.8)$ & $473(15.8)$ \\
\hline \multicolumn{4}{|l|}{ Gender } \\
\hline Male & $667(12.2)$ & 433 (10.6) & $234(16.8)$ \\
\hline Female & $675(10.5)$ & $436(9.0)$ & $239(14.9)$ \\
\hline Age (years)* & $16.7(1.3)$ & $16.8(1.1)$ & $16.4(1.5)$ \\
\hline \multicolumn{4}{|l|}{ Grade } \\
\hline 10 & $454(11.5)$ & $266(9.1)$ & $188(18.3)$ \\
\hline 11 & $452(11.4)$ & $325(11.1)$ & $127(12.5)$ \\
\hline 12 & $436(10.9)$ & $278(9.6)$ & $158(14.1)$ \\
\hline \multicolumn{4}{|l|}{ Living arrangement } \\
\hline With both parents & $690(10.7)$ & $476(9.5)$ & $214(14.7)$ \\
\hline With only father or mother & $219(11.5)$ & $128(9.2)$ & $91(17.8)$ \\
\hline With others & $428(12.2)$ & $263(10.6)$ & $165(16.4)$ \\
\hline \multicolumn{4}{|l|}{ Pocket money (RMB) } \\
\hline$<100$ & $600(11.0)$ & $378(9.3)$ & $222(16.3)$ \\
\hline $100-299$ & $454(10.3)$ & $313(9.5)$ & $141(12.9)$ \\
\hline$>300$ & $274(13.8)$ & $168(11.5)$ & $106(20.4)$ \\
\hline \multicolumn{4}{|l|}{ Family economic status } \\
\hline Above average & $118(13.9)$ & $76(11.4)$ & $42(22.5)$ \\
\hline Average & $683(10.5)$ & $463(9.3)$ & $220(14.3)$ \\
\hline Below average & $536(12.0)$ & $327(10.2)$ & $209(16.7)$ \\
\hline \multicolumn{4}{|l|}{ Family relationships } \\
\hline Good & $895(10.3)$ & 585 (8.9) & $310(14.8)$ \\
\hline Normal & $282(12.8)$ & $176(11.2)$ & $106(16.9)$ \\
\hline Difficult & $160(16.1)$ & $105(14.5)$ & $55(20.7)$ \\
\hline \multicolumn{4}{|l|}{ Academic stress } \\
\hline Above average & $193(12.5)$ & $92(10.2)$ & $101(15.6)$ \\
\hline Average & $522(10.5)$ & $286(8.4)$ & $236(14.9)$ \\
\hline Below average & $625(11.7)$ & $489(10.6)$ & $136(17.8)$ \\
\hline \multicolumn{4}{|l|}{ Classmate relationships } \\
\hline Good & $720(10.7)$ & $487(9.4)$ & $233(15.0)$ \\
\hline Average & $553(11.6)$ & $335(9.8)$ & $218(16.3)$ \\
\hline Poor & $63(18.3)$ & $44(17.6)$ & $19(20.2)$ \\
\hline \multicolumn{4}{|l|}{ Relationships with teachers } \\
\hline Good & $483(10.5)$ & 304 (8.9) & $179(14.8)$ \\
\hline Average & $718(11.0)$ & $474(9.6)$ & $244(15.1)$ \\
\hline Poor & $140(18.9)$ & $90(15.8)$ & $50(29.4)$ \\
\hline \multicolumn{4}{|l|}{ Parents engaged in NMUPD } \\
\hline No & $1241(10.8)$ & $800(9.3)$ & $441(15.2)$ \\
\hline Yes & $101(24.9)$ & $69(23.2)$ & $32(29.9)$ \\
\hline \multicolumn{4}{|l|}{ Friends engaged in NMUPD } \\
\hline No & $1227(10.8)$ & $795(9.3)$ & $432(15.1)$ \\
\hline Yes & $115(21.2)$ & $74(18.6)$ & $41(28.3)$ \\
\hline \multicolumn{4}{|l|}{ Cigarette smoking } \\
\hline No & 1059 (10.3) & $710(9.0)$ & $349(14.6)$ \\
\hline Yes & $283(17.6)$ & $159(15.9)$ & $124(20.5)$ \\
\hline \multicolumn{4}{|l|}{ Alcohol drinking } \\
\hline No & $975(11.5)$ & $635(9.9)$ & $340(16.5)$ \\
\hline Yes & $367(10.7)$ & $234(9.4)$ & $133(14.2)$ \\
\hline \multicolumn{4}{|l|}{ Feel lonely } \\
\hline$<1$ day/week & $550(9.5)$ & $354(8.1)$ & $196(13.7)$ \\
\hline 1-4 days/week & $570(12.7)$ & $365(10.9)$ & $205(17.7)$ \\
\hline$>4$ days/week & $193(13.6)$ & $128(12.0)$ & $65(18.2)$ \\
\hline \multicolumn{4}{|l|}{ Suicide behaviour } \\
\hline Never & $1194(10.6)$ & $767(9.1)$ & $427(15.2)$ \\
\hline Considered & $69(20.1)$ & $46(19.7)$ & $23(20.7)$ \\
\hline Attempted & $50(35.2)$ & $36(34.6)$ & $14(36.8)$ \\
\hline
\end{tabular}

${ }^{*}$ Age data are presented as the means (SD).

GHS, general high school; NMUPD, non-medical use of prescription drugs; NMUPPR, non-medical use of prescription pain relievers; VHS, vocational high school. 
Table 3 Classes, sources and motivations for NMUPPR among GHS and VHS students

\begin{tabular}{|c|c|c|c|c|}
\hline Variables & Total, n (\%) & GHS, n (\%) & VHS, n (\%) & p Value* \\
\hline Total & $11906(100)$ & $8905(100)$ & $3001(100)$ & \\
\hline \multicolumn{5}{|l|}{ Class of pain relievers } \\
\hline Scattered analgesics & $685(5.8)$ & $434(4.9)$ & $251(8.4)$ & $<0.001$ \\
\hline Codeine & $661(5.5)$ & $443(5.0)$ & $218(7.3)$ & $<0.001$ \\
\hline Percocet & $647(5.4)$ & $416(4.7)$ & $231(7.7)$ & $<0.001$ \\
\hline Tramadol & $73(0.6)$ & $54(0.6)$ & $19(0.6)$ & 0.871 \\
\hline \multicolumn{5}{|l|}{ Source of pain relievers } \\
\hline From peers & $746(6.3)$ & $522(5.9)$ & $224(7.5)$ & $<0.001$ \\
\hline From family members & $241(2.0)$ & $130(1.5)$ & $111(3.7)$ & $<0.001$ \\
\hline Others & $551(4.6)$ & 348 (3.9) & $203(6.8)$ & $<0.001$ \\
\hline \multicolumn{5}{|l|}{ Motivation for NMUPPR } \\
\hline To relax or relieve tension & $580(4.9)$ & $391(4.4)$ & $189(6.3)$ & $<0.001$ \\
\hline To experiment & $310(2.6)$ & $206(2.3)$ & $104(3.5)$ & 0.001 \\
\hline To get high & $294(2.5)$ & $192(2.2)$ & $102(3.4)$ & $<0.001$ \\
\hline Other & $482(4.0)$ & $315(3.5)$ & $167(5.6)$ & $<0.001$ \\
\hline
\end{tabular}

relationship between NMUPPR and grade is likely to vary depending on the substance.

The final logistic regression model also revealed that the risk of NMUPPR increased among students who reported receiving more than $100 \mathrm{RMB}$ as pocket money per month, and similar results were found in the study of Wang et $a l^{21}$ in Guangdong. It is possible that students with more pocket money have more access to prescription drugs. Additionally, we found that below-average family economic status was slightly negatively correlated with NMUPPR (AOR $=0.77,95 \%$ CI 0.60 to 0.98). Similarly, Hanson's research in the USA demonstrated that high socioeconomic status teens were more likely to use substances than low socioeconomic status teens. ${ }^{34}$ It is possible that compared with students who reported above-average family economic status, students from lower-income families had less pocket money; thus, they had less access to prescription drugs. Parental factors have been associated with non-medical prescription drug use in several studies. In the USA, Herman-Stahl's research reported that adolescents who had a high level of family conflict were more likely than their counterparts to engage in non-medical use of prescription stimulants. ${ }^{35}$ This study also found that difficult family relationships were associated with NMUPPR, with an increased odds of $26 \%$ ( $\mathrm{AOR}=1.26,95 \%$ CI 1.02 to 1.54). Notably, this study found that students having parents who engaged in non-medical prescription drug use were at a higher risk for NMUPPR, and previous studies also indicated that adolescents having parents who used substances were at an increased risk for substance use. ${ }^{23}$ The present results emphasised the negative consequence that parental factors can have in terms of students' NMUPPR and the importance of improving parental monitoring practices of both their own and their children's non-medical drug use. Twombly's research in the USA suggested that it is necessary to improve parents' and adolescents' awareness of the risks of non-medical use of any prescription drug. ${ }^{37}$

In addition, frequent substance use is negatively associated with school-related factors. ${ }^{38}$ In this study, we found that students who had poor relationships with teachers were more likely to engage in NMUPPR. The finding is consistent with previous studies that have suggested that engagement and positive teacher-pupil relationships are strongly negatively associated with all substance use categories. ${ }^{39}$ Previous studies have indicated that students with friends who engaged in nonmedical prescription drug use were at a higher risk of NMUPPR. ${ }^{40}{ }^{41}$ Peers may serve as role models, influence personal attitudes towards substance use and/or provide access, encouragement and social settings for substance use. ${ }^{14}$ In this study, we found that students having friends who non-medically used prescription drugs were more likely to be involved in NMUPPR, and the NMUPPR among high school students were most commonly obtained from peers. Similarly, McCabe's study in the USA suggested that the majority of students obtained prescription pain relievers for non-medical use from peers. ${ }^{1}$ Therefore, prevention and effective interventions are needed to target school-related factors, especially the bidirectional influence between peers. Students need to be educated about the potential dangers associated with providing abusable prescription pain medications to their peers. ${ }^{13}$

Consistent with previous studies in China and the USA showing that cigarette smoking increased the prevalence rate of NMUPPR, ${ }^{21}{ }^{42}$ this study revealed that cigarette smokers were 1.53 (95\% CI 1.29 to 1.82 ) times more likely to engage in NMUPPR than non-smokers. Although a prior study in Sweden has reported a relationship between alcohol drinking and non-medical use of analgesics, ${ }^{24}$ we did not find this association in this 
Table 4 Predictors of NMUPPR based on a two-level multivariate logistic regression model

\begin{tabular}{l}
\hline Variables \\
\hline School level \\
School category \\
General high school \\
Vocational high school \\
Individual level \\
Gender \\
Female \\
Male \\
Age (years) \\
Grade \\
10 \\
11 \\
12
\end{tabular}

AOR $(95 \% \mathrm{Cl})$

Living arrangement

With both parents

With only father or mother

With others

Pocket money (RMB)

$<100$

100-299

$>300$

Family economic status

Above average

Average

Below average

Family relationships

Good

Normal

Difficult

Academic stress

Above average

Average

Below average

Classmate relationships

Good

Average

Poor

Relationships with teachers

Good

Average

Poor

Parents engaged in NMUPD

No

Yes

Friends engaged in NMUPD

No

Yes

Cigarette smoking

No

Yes

Alcohol drinking

No

Yes

Feel lonely

$<1$ day/week

1-4 days/week

$>4$ days/week
1.00 (reference)

1.64 (1.42 to 1.89$)^{*}$

1.00

0.98 (0.86 to 1.12$)$

0.99 (0.93 to 1.05$)$

1.00

1.27 (1.09 to 1.46$)$

1.53 (0.99 to 2.37 )

1.00

0.89 (0.78 to 1.03$)$

0.97 (0.82 to 1.15$)$

1.00

$1.21(1.02 \text { to } 1.43)^{*}$

$1.24(1.04 \text { to } 1.47)^{\star}$

1.00

1.03 (0.90 to 1.17$)$

$0.77(0.60 \text { to } 0.98)^{*}$

1.00

1.12 (0.89 to 1.41$)$

$1.26(1.02 \text { to } 1.54)^{\star}$

1.00

1.13 (0.97 to 1.33$)$

1.20 (0.98 to 1.46$)$

1.00

1.25 (0.91 to 1.72$)$

1.24 (0.90 to 1.72 )

1.00

$1.50(1.20 \text { to } 1.89)^{*}$

$1.57(1.23 \text { to } 2.01)^{*}$

1.00

$2.31(1.79 \text { to } 2.98)^{*}$

1.00

$1.75(1.38 \text { to } 2.22)^{*}$

1.00

$1.53(1.29 \text { to } 1.82)^{*}$

1.00

1.02 (0.89 to 1.17 )

1.00

0.86 ( 0.71 to 1.04$)$

1.06 (0.87 to 1.29$)$

\begin{tabular}{ll} 
Table 4 Continued & \\
\hline Variables & AOR $(95 \% \mathrm{Cl})$ \\
\hline Suicide behaviour & \\
$\quad$ Never & 1.00 \\
Considered & $3.47(2.34 \text { to } 5.15)^{\star}$ \\
Attempted & $2.08(1.29 \text { to } 3.35)^{\star}$ \\
\hline
\end{tabular}

${ }^{*}$ According to the two-level multivariate logistic regression model with adjustment for other variables, $p<0.05$.

AOR, adjusted OR; NMUPD, non-medical use of prescription drugs; NMUPPR, non-medical use of prescription pain relievers.

study. This discrepancy may be related to the definition or extent of alcohol drinking. Nonetheless, interventions that target students who have already initiated substance use may be effective in reducing use. ${ }^{43}$

Regarding the psychosocial-related factors, many studies in European countries and the USA have indicated that mental health is closely related to substance use. ${ }^{14}{ }^{44}$ In this study, we found that the most prevalent motivation for NMUPPR among students was 'to relax or relieve tension', and similar results have been reported in McCabe's study in the USA. ${ }^{45}$ Additionally, NMUPPR was reported to be associated with suicidal behaviour among Mississippi youth. ${ }^{15}$ Consistent with these findings, this study found that considering or attempting suicide was positively correlated with NMUPPR and that attempting suicide increased the odds of NMUPPR by $186 \%$ (AOR=2.86, 95\% CI 1.96 to 4.17). Therefore, students who report poor psychosocialrelated factors should be a primary focus, and proper interventions should be provided for these individuals.

This study has noteworthy strengths, including the analysis of survey data that were collected from a large-scale sample of GHS and VHS students. Furthermore, individual-level and school-level factors were incorporated in a two-level multivariate logistic regression model to select independent predictors of NMUPPR simultaneously. Importantly, we observed the differences in NMUPPR between GHS and VHS students. Despite these strengths, the results of our analyses are tempered by some methodological limitations that should be considered. First, the results cannot be generalised to all adolescents because this sample only included high school students and did not include individuals who had dropped out of school or were not present in school on the day of survey administration. Second, the data are subject to potential bias introduced by the administration of sensitive behaviours via selfreport surveys in a school setting. Finally, the crosssectional nature of the study presents several limitations; thus, longitudinal studies that enrol adolescents in more diverse age groups and employ more diverse measures of current use are needed to examine the patterns of NMUPPR.

In conclusion, NMUPPR among Chinese high school students is a significant public health problem that warrants the attention of policymakers, researchers and 
practitioners. Effective interventions to prevent and control NMUPPR among high school students are highly recommended and should consider the influence of both individual-level and school-level factors. First, parents and schools should focus on NMUPPR among adolescents, particularly those who struggle in psychosocial-related or school-related relationships. Furthermore, educational campaigns that are directed at families and schools are needed to improve awareness of the serious consequences of NMUPPR. Moreover, policies that aim to control the sale of prescription pain relievers to adolescents without a doctor's prescription are highly recommended. Finally, a well-established surveillance programme to supervise and control nonmedical prescription drug use and to predict trends in long-term negative outcomes of NMUPPR among adolescents (similar to MTF in the USA) is expected to be developed in China.

Acknowledgements The authors gratefully acknowledge not only the contribution of the Chongqing Education Bureau and its participating schools, but also the language editing done by the School of Public Health, Sun Yat-sen University.

Contributors $L G$ and $C L$ searched the literature, conceived the study, designed the study, analysed the data, interpreted the results and drafted the report. YX and JD organised the study and collected and analysed the data. $\mathrm{YH}, \mathrm{XG}, \mathrm{PL}, \mathrm{HW}$ and JZ collected the data, interpreted the results and obtained funding.

Funding This study was supported by the Center for ADR Monitoring of Guangdong.

Ethics approval The study received approval from the Sun Yat-sen University, School of Public Health Institutional Review Board.

Competing interests None declared.

Provenance and peer review Not commissioned; externally peer reviewed.

Data sharing statement No additional data are available.

Open Access This is an Open Access article distributed in accordance with the Creative Commons Attribution Non Commercial (CC BY-NC 4.0) license, which permits others to distribute, remix, adapt, build upon this work noncommercially, and license their derivative works on different terms, provided the original work is properly cited and the use is non-commercial. See: http:// creativecommons.org/licenses/by-nc/4.0/

\section{REFERENCES}

1. McCabe SE, Teter CJ, Boyd CJ. Illicit use of prescription pain medication among college students. Drug Alcohol Depend 2005;77:37-47.

2. McCabe SE, Teter CJ, Boyd CJ. Medical use, illicit use and diversion of prescription stimulant medication. J Psychoactive Drugs 2006;38:43-56.

3. Novak SP, Calvin SL, Glasheen C, et al. The epidemiology and treatment of prescription drug disorders in the United States. In: Uehara T, ed. Psychiatric disorders-trends and developments. InTech, 2011. http://www.intechopen.com/books/psychiatricdisorders-trends-and-developments/the-epidmiology-and-treatmentof-prescription-drug-disorders-in-the-united-states

4. Substance Abuse and Mental Health Services Administration. The NSDUH Report: Substance Use and Mental Health Estimates from the 2013 National Survey on Drug Use and Health: Overview of findings, 2013.

5. Substance Abuse and Mental Health Services Administration. Misuse of prescription drugs, 2006.

6. Abuse of prescription pain medication risk s heroin use. http:// d14rmgtrwzf5a.cloundfront.net/sites/default/files/infographic_presc_ heroin.pdf.
7. Crockett LJ, Beal SJ. The life course in the making: gender and the development of adolescents' expected timing of adult role transitions. Dev Psychol 2012;48:1727-38.

8. McCabe SE, West BT, Morales M, et al. Does early onset of nonmedical use of prescription drugs predict subsequent prescription drug abuse and dependence? Results from a national study. Addiction 2007;102:1920-30.

9. Fleary SA, Heffer RW, McKyer EL. Understanding nonprescription and prescription drug misuse in late adolescence/young adulthood. $J$ Addict 2013;2013:709207.

10. Young AM, Glover N, Havens JR. Nonmedical use of prescription medications among adolescents in the United States: a systematic review. J Adolesc Health 2012;51:6-17.

11. Jones CM. Frequency of prescription pain reliever nonmedical use: 2002-2003 and 2009-2010. Arch Intern Med 2012;172:1265-7.

12. Zacny J, Bigelow G, Compton P, et al. College on problems of drug dependence taskforce on prescription opioid non-medical use and abuse: position statement. Drug Alcohol Depend 2003;69:215-32.

13. Boyd CJ, Esteban MS, Teter CJ. Medical and nonmedical use of prescription pain medication by youth in a Detroit-area public school district. Drug Alcohol Depend 2006;81:37-45.

14. Kokkevi AE, Arapaki AA, Richardson $C$, et al. Further investigation of psychological and environmental correlates of substance use in adolescence in six European countries. Drug Alcohol Depend 2007;88:308-12.

15. Viana AG, Trent L, Tull MT, et al. Non-medical use of prescription drugs among Mississippi youth: constitutional, psychological, and family factors. Addict Behav 2012;37:1382-8.

16. Lin WH, Yi CC. Educational tracking and juvenile deviance in Taiwan: direct effect, indirect effect, or both. Int J Offender Ther Comp Criminol 2014. doi:10.1177/0306624X14549440

17. Haug S, Schaub MP, Salis GC, et al. Predictors of hazardous drinking, tobacco smoking and physical inactivity in vocational school students. BMC Public Health 2013;13:475.

18. Kim SS, Williams DR. Perceived discrimination and self-rated health in South Korea: a nationally representative survey. PLOS ONE 2012;7:e30501.

19. Pankrat'Ev V, Antipina NA, Roshchupkin AA, et al. [Prevalence of alcohol use among school children and vocational school students in Murmansk]. Probl Sotsialnoi Gig Zdravookhranenniiai Istor Med 2001;2:20-1.

20. Heo J, Oh J, Subramanian SV, et al. Household and school-level influences on smoking behavior among Korean adolescents: a multilevel analysis. PLOS ONE 2014;9:e98683.

21. Wang $\mathrm{H}$, Deng J, Zhou $\mathrm{X}$, et al. The nonmedical use of prescription medicines among high school students: a cross-sectional study in Southern China. Drug Alcohol Depend 2014;141:9-15.

22. Johnston LD, O'Malley PM, Miech RA. Monitoring the Future national results on adolescent drug use: Overview of key findings, 2013. 2014. http://www.monitoringthefuture.org/pubs/monographs/ mtf-overview2013.pdf

23. Shorey RC, Fite PJ, Elkins SR, et al. The association between problematic parental substance use and adolescent substance use in an ethnically diverse sample of 9 th and 10th graders. J Prim Prev 2013;34:381-93.

24. Abrahamsson T, Hakansson A. Nonmedical prescription drug use (NMPDU) in the Swedish general population-correlates of analgesic and sedative use. Subst Use Misuse 2015;50:148-55.

25. Zhang M, Chu K. The research of traditional Chinese medicines on relieving pain (in Chinese). Strait Pharm J 2008;20:93-6.

26. Sun $\mathrm{P}$, Johnson CA, Palmer $\mathrm{P}$, et al. Concurrent and predictive relationships between compulsive internet use and substance use: findings from vocational high school students in China and the USA Int J Environ Res Public Health 2012;9:660-73.

27. Franke AG, Bonertz C, Christmann M, et al. Non-medical use of prescription stimulants and illicit use of stimulants for cognitive enhancement in pupils and students in Germany. Pharmacopsychiatry 2011;44:60-6

28. Hansen J, Hanewinkel R, Maruska K, et al. The 'Eigenstandig werden' prevention trial: a cluster randomised controlled study on a school-based life skills programme to prevent substance use onset. BMJ Open 2011;1:e000352.

29. Wu LT, Pilowsky DJ, Patkar AA. Non-prescribed use of pain relievers among adolescents in the United States. Drug Alcohol Depend 2008;94:1-11.

30. Martins SS, Kim JH, Chen L, et al. Nonmedical prescription drug use among US young adults by educational attainment. Soc Psychiatry Psychiatr Epidemiol 2015;50:713-24.

31. Shield KD, lalomiteanu A, Fischer B, et al. Non-medical use of prescription opioids among Ontario adults: data from the 2008/2009 CAMH Monitor. Can J Public Health 2011;102:330-5. 
32. Nakawaki B, Crano WD. Predicting adolescents' persistence, nonpersistence, and recent onset of nonmedical use of opioids and stimulants. Addict Behav 2012;37:716-21.

33. McCabe SE, Boyd CJ, Young A. Medical and nonmedical use of prescription drugs among secondary school students. J Adolesc Health 2007;40:76-83.

34. Hanson MD, Chen E. Socioeconomic status and substance use behaviors in adolescents: the role of family resources versus family social status. J Health Psychol 2007;12:32-5.

35. Herman-Stahl MA, Krebs CP, Kroutil LA, et al. Risk and protective factors for nonmedical use of prescription stimulants and methamphetamine among adolescents. J Adolesc Health 2006;39:374-80.

36. Nargiso JE, Ballard EL, Skeer MR. A systematic review of risk and protective factors associated with nonmedical use of prescription drugs among youth in the United States: a social ecological perspective. J Stud Alcohol Drugs 2015;76:5-20.

37. Twombly EC, Holtz KD. Teens and the misuse of prescription drugs: evidence-based recommendations to curb a growing societal problem. J Prim Prev 2008;29:503-16.

38. Hotton T, Haans D. Alcohol and drug use in early adolescence. Health Rep 2004;15:9-19.

39. Markham WA, Young $\mathrm{R}$, Sweeting $\mathrm{H}$, et al. Does school ethos explain the relationship between value-added education and teenage substance use? A cohort study. Soc Sci Med 2012;75:69-76.

40. Kokkevi A, Fotiou A, Arapaki A, et al. Prevalence, patterns, and correlates of tranquilizer and sedative use among European adolescents. J Adolesc Health 2008;43:584-92.

41. Sung HE, Richter L, Vaughan R, et al. Nonmedical use of prescription opioids among teenagers in the United States: trends and correlates. J Adolesc Health 2005;37:44-51.

42. Collins $\mathrm{D}$, Abadi $\mathrm{MH}$, Johnson $\mathrm{K}$, et al. Non-medical use of prescription drugs among youth in an Appalachian population: prevalence, predictors, and implications for prevention. J Drug Educ 2011;41:309-26.

43. Havens JR, Young AM, Havens CE. Nonmedical prescription drug use in a nationally representative sample of adolescents: evidence of greater use among rural adolescents. Arch Pediatr Adolesc Med 2011;165:250-5.

44. Substance Abuse and Mental Health Services Administration. Results from the 2008 national survey on drug use and health National Findings (No. SMA 09-4434). Rockville, MD: Office of Applied Studies, 2009.

45. McCabe SE, Cranford JA. Motivational subtypes of nonmedical use of prescription medications: results from a national study. J Adolesc Health 2012;51:445-52. 